\title{
Analysis of Cooling Ball Stress to Prevent Spontaneous Ignition of Coal Stockpiles
}

\author{
Min-Seok Jie ${ }^{1}$, Seung-Hun Kim ${ }^{2}$, Chan-Syb Yeum ${ }^{3}$ and Won-Hyuck Choi ${ }^{4 *}$ \\ ${ }^{1,4}$ Department of Avionics Engineering Hanseo University \\ 236-49, Gomseom-ro, Nam-myeon, Taean-gun, 32158 Chungcheongnam-do, \\ Republic of Korea \\ ${ }^{2}$ Department of Aeronautical Systems Engineering, 236-49, Gomseom-ro, Nam- \\ myeon, Taean-gun, 32158 Chungcheongnam-do, Republic of Korea \\ ${ }^{3}$ People i Co., Ltd., 49, Techno 8-ro, Yuseong-gu, Daejeon, Republic of Korea \\ \{1hoiwh, ${ }^{4}$ jiems\}@hanseo.ac.kr, ${ }^{2}$ kimsh753@naver.com
}

\begin{abstract}
Damage caused by spontaneous ignition in coal stockpile is proportional to the increase in coal thermal power plant. The problem of spontaneous ignition is not only severe economic damage but also a typical plant damage caused by harmful gases generated during the fire. Because coal is porous, it causes oxygen to be absorbed in the amount of oxygen per unit weight of oxygen, resulting in low humidity and low thermal conductivity. The cause and effect of spontaneous ignition are very complex, so it is difficult to prevent it beforehand and once it is difficult to digest it, it is difficult to digest it. This study examines structural stability by conducting a structural analysis of the cooling ball system to prevent spontaneous combustion of coal stockpile plants and external pressures.
\end{abstract}

Keywords: Pressure Vessel, Spontaneous Ignition, Coal Stockpile, Cooling Ball, Nitrogen, Pressures Stress

\section{Introduction}

The damage caused by spontaneous ignition of coal stockpile often occurs in proportion to the increase in the amount of low carbon used in coal-fired power plants. It is not only a serious economic damage but also a typical example of causing environmental pollution caused by harmful gas Power plant damage.

In the related industry, physical or chemical solutions are proposed to solve the problem of low self-ignition spontaneous ignition, but the cost and effect of expensive facility construction and operation are not ensured and the field is suffering from difficulties. A coal-fired 500-MW thermal power plant will have approximately six 500-ton capacity coal reservoirs, five of which will be supplied with normal coal, and the other will have a reserve coal reserve and is operated with low-profile. When the coal is loaded in the outdoors, the powder dust is blown, polluting the environment of the workplace, and a part of the raw material is lost due to the wind. Recently, the problem of spontaneous ignition is getting bigger because it is stored mainly in a closed reservoir. In addition, the gas generated in the spontaneous ignition process may cause gas explosion if not released to the outside, and spontaneous ignition in the storage facility may induce dust explosion. In this way, safety management for prevention of spontaneous ignition is very important in the space where coal is stored and measures against fire occurrence are needed. One method of this countermeasure is an automatic cooling ball device which emits a digestive liquid and lowers the temperature when the temperature of the low - leaning is above a certain temperature by a cooling ball extinguishing method.

Received (December 26, 2017), Review Result (March 19, 2018), Accepted (March 26, 2018) 
This study is a study on the structural safety of the cooling ball device, and it performs structural analysis on the pressure of the inner tank against the gas pressure and the structural analysis of the cooling ball shape against the external pressure and evaluates the structural safety [1].

\section{Design Theory}

When a cooling ball is buried in a coal stockpile with coal, the cooling ball is likely to be damaged due to the weight of the coal. The cooling ball is in the form of a pressure vessel. The inner tank is subjected to internal pres sure by the digestive fluid. The external shape is buried in the coal stockpile and receives the external pressure of the coal.

The stress acting on the thin cylindrical container can be divided into $x$ direction stress and $y$ direction stress, and $y$ direction stress is calculated as follows. The load $p$ acting on the wall can be expressed as the product of the pressure $p$ acting on the inside and the area [2].
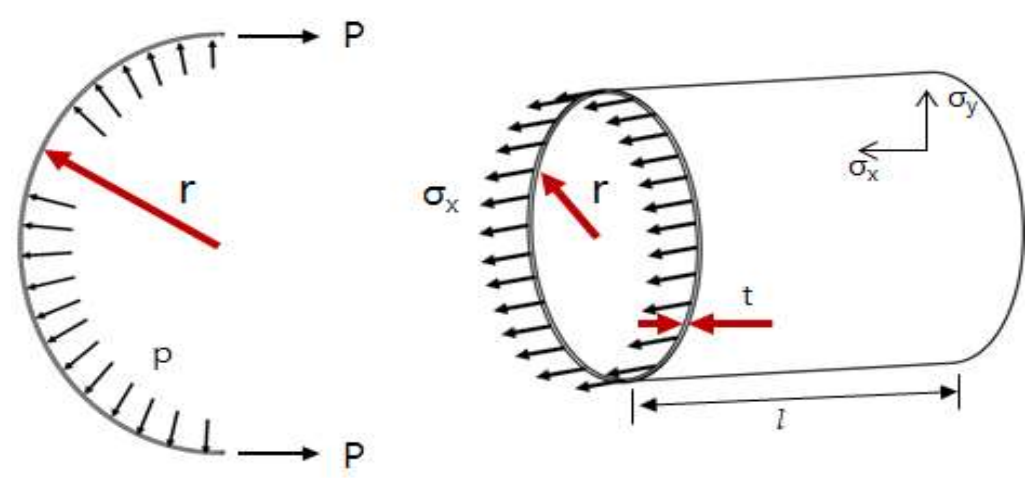

Figure 1. Cylindrical Pressure Vessel

The stress acting on the thin cylindrical container as shown in Figure 1 can be divided into the $\mathrm{x}$ direction stress and the $\mathrm{y}$ a direction stress, and the $\mathrm{y}$ direction stress is calculated as follows. The load $(P)$ acting on the wall can be expressed as the product of the pressure (p) acting on the inside and the area [3].

$$
P=p d_{i} l
$$

$$
\begin{aligned}
& \mathrm{t}=\text { Thickness } \\
& \mathrm{l}=\text { Length in } \mathrm{x} \text { direction } \\
& d_{i}=\text { Inner diameter }
\end{aligned}
$$

$$
\sigma_{y}=\frac{p d_{i} l}{2 t l}=\frac{p d_{i}}{2 t}
$$

The stress as in Equation 2 is called circumferential stress or hoop stress. In addition, if the stress acting on the cylindrical cross section in the $\mathrm{x}$ direction is plotted, the area of the cross section in the $\mathrm{x}$ direction is $\pi, d_{i}, t$, and the load $\mathrm{P}$ is the equation $\frac{p \pi d_{i}^{2}}{4}$, so the $\mathrm{x}$ direction stress is as follows.

$$
\sigma_{x}=\frac{p \frac{\pi}{4} d_{i}^{2}}{\pi d t}=\frac{p d_{i}}{4 t}
$$


The direction stress of Equation 3 is called longitudinal stress and axial stress. Eq. 2 and Eq. 3, the stress is twice as large and the direction stress is large at the same condition $[4,5]$.

Then, the theoretical expression of a spherical pressure vessel having a diameter $\mathrm{d}$, which is a cooling ball shape, can be described as follows. The load $\mathrm{P}=\frac{1}{4} p \pi d_{i}^{2}$ acting on the thin wall surface and the area of the cross section is $\pi, d_{i}, t$. The stress in the $\mathrm{x}$ direction is expressed by the following equation.

$$
\sigma_{\text {sphere }}=\frac{\frac{1}{4} p \pi d_{i}^{2}}{\pi d_{i} t}=\frac{p d_{i}}{4 t}
$$

Equation 4 is equivalent to Equation 3 in the $\mathrm{x}$ direction. Therefore, the cooling balls are Eq. 4 is applied. In the case of external pressure, the equation is as follows $d_{o}$ is the outer diameter [5] [6].

$$
\sigma_{o}=\frac{p d_{o}}{2 t}
$$

\section{Structural Analysis Result}

\subsection{Structural Analysis of Internal Gas Tank}

The cooling ball is composed of an internal tank in which liquid nitrogen is contained, a control unit, a fire extinguishing liquid injection nozzle, an external case, and a solenoid valve. Figure 2 shows the assembled state of the cooling ball and shows the cutting plane.

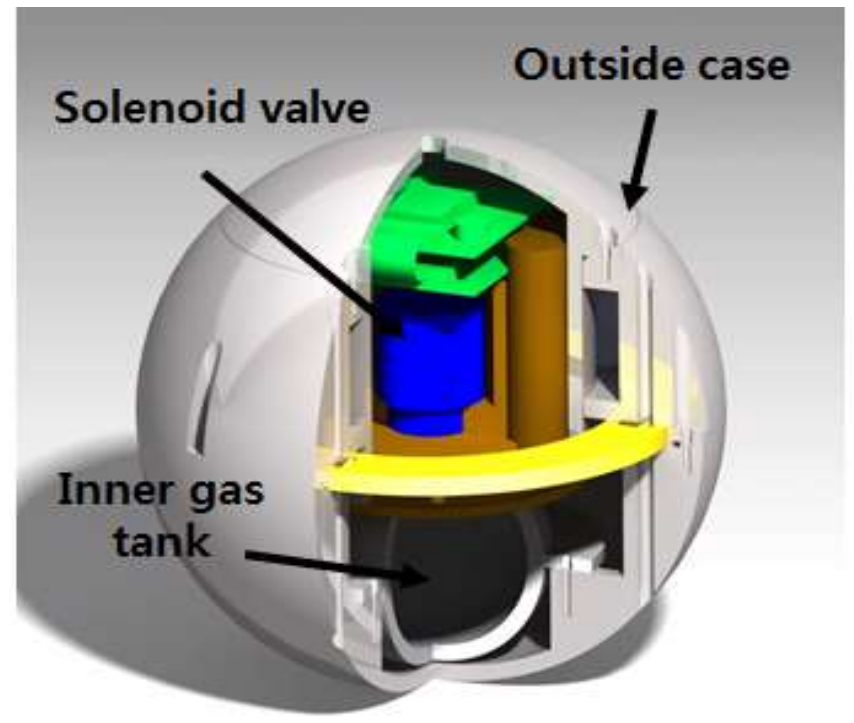

Figure 2. Cutaway of Cooling Ball

Figure 3 shows the shape of the inner gas tank, which is fixed by an external flange. The inside pressure is $3.0 \mathrm{MPa}$ with liquefied nitrogen [7]. 


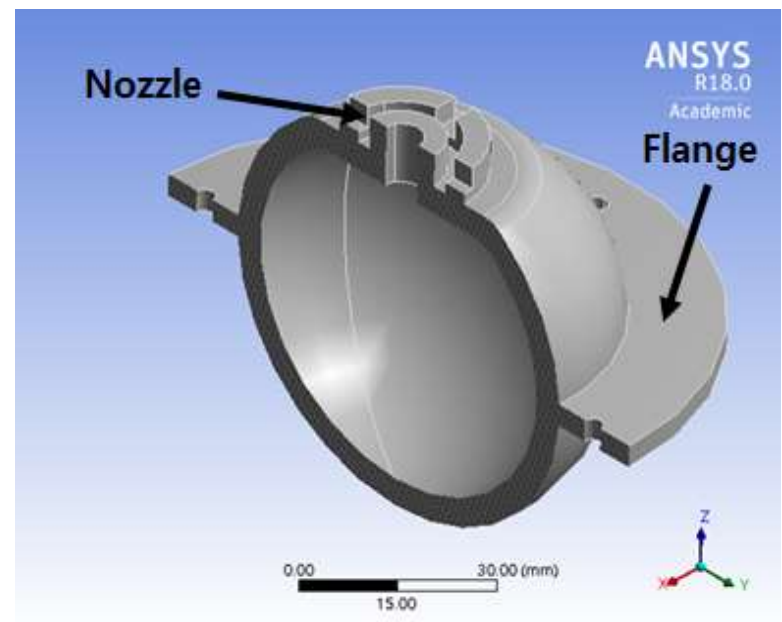

Figure 3. Inner Gas Tank Real Shape

As mentioned in the theory, when the pressure vessel is a thin cell structure when the thickness $t$ is smaller than 10 times the diameter $d$, the inner tank of the cooling ball has a ratio of the diameter $d$ and the thickness $t$ to 0.0833 It is a thin cell structure.

Table 1. The Thin Shell Classification of Pressure Vessel for Inner Tank

\begin{tabular}{|c|c|c|c|c|}
\hline Division & $\mathrm{t}(\mathrm{mm})$ & $\mathrm{d}_{\mathrm{i}}(\mathrm{mm})$ & $\mathrm{t} / \mathrm{d}$ & Standard \\
\hline $\begin{array}{c}\text { Inner } \\
\text { Tank }\end{array}$ & 5 & 60 & 0.0833 & $\begin{array}{c}\mathrm{t} / \mathrm{d} \leq 1 / 10 \\
\text { to shell }\end{array}$ \\
\hline
\end{tabular}

Structural analysis first analyzes the shape of a simple internal tank without a flange and compares and verifies the output value with the theoretical value. And the actual shape with the flange. Theoretical calculations are based on Eq. 4 was used.

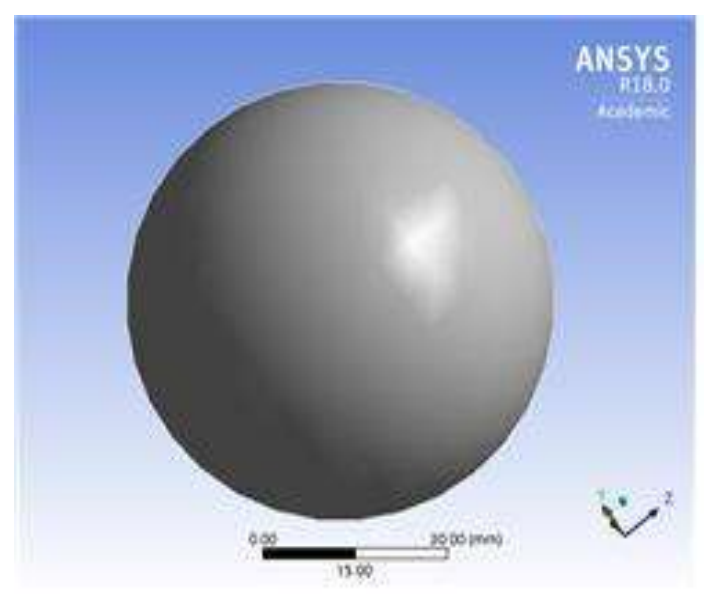

\section{Figure 4. Inner Gas Tank Modeling Simplified}

Here, the inner diameter di was $60 \mathrm{~mm}$, the thickness $\mathrm{t}$ was $5 \mathrm{~mm}$, and the pressure $\mathrm{P}$ was $3.0 \mathrm{MPa}$ as the inner pressure. As a result, the theoretical calculation value was calculated to be $9.0 \mathrm{MPa}$. Figure 4 shows a simple shape without a flange. CATIA program was used for shape design.

Structural analysis was performed using ANSYS R18.0 under the condition that the internal pressure of 3.0MPa was applied to the entire interior. Figure 5 represents the mesh (mesh), which is divided into $1,152[8,9]$. 


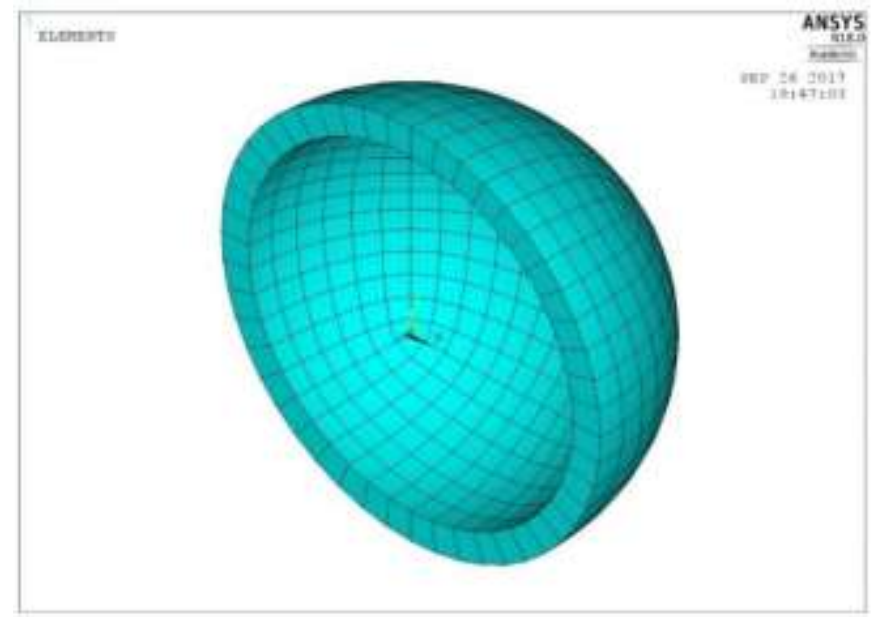

Figure 5. Mesh of Inner Gas Tank Simplified (ISO view)

Figures 6 and 7 show the result of Principal Stress analysis. The unit is (MPa). As shown, the inner surface is stressed up to $9.11 \mathrm{MPa}$ and the outer surface is subjected to stress of 7.59MPa.

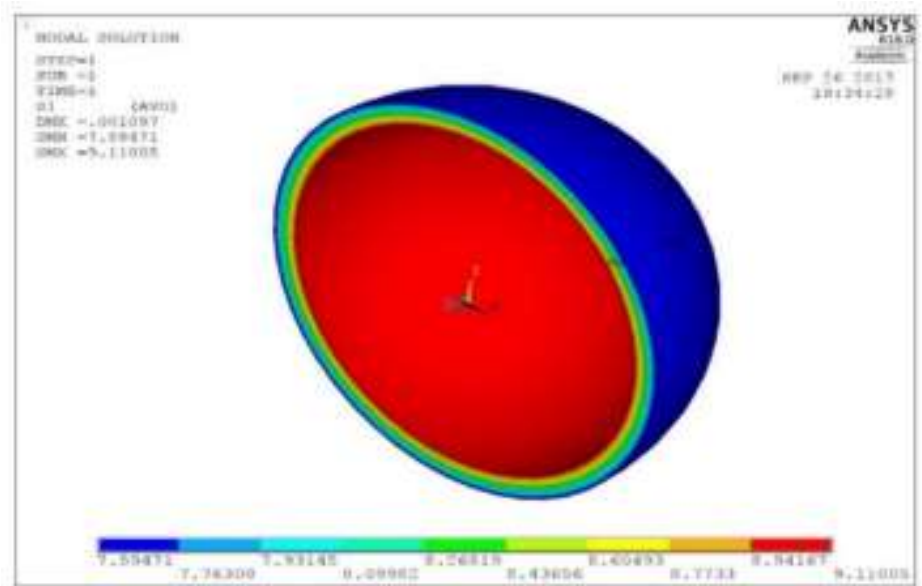

Figure 6. Principal Stress Distribution of Cooling Ball (ISO view)

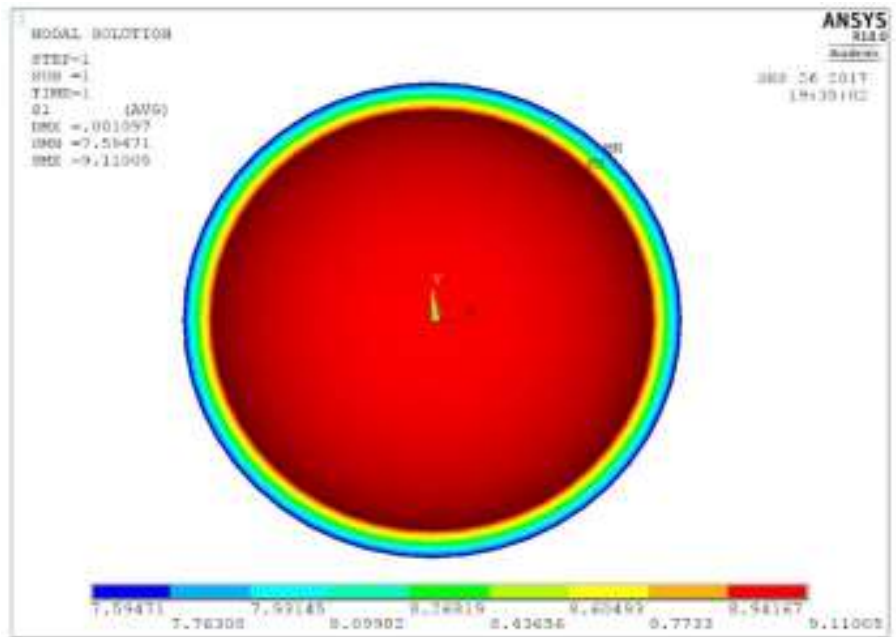

Figure 7. Principal Stress Distribution of Cooling Ball (Inside View) 
Table 2 compares the results of ANSYS with those calculated by theoretical equations. In general, if the error is within 5\%, the result is excellent, and the error is $1.2 \%$ based on the theoretical formula.

\section{Table 2. The Comparison of Calculated Stress and Analyzed Stress (Simplified)}

\begin{tabular}{|c|c|}
\hline Division & Stress \\
\hline Theoretical Value & $9.00 \mathrm{Mpa}$ \\
\hline Interpreted Value & $9.11 \mathrm{Mpa}$ \\
\hline Error & $1.22 \%$ \\
\hline
\end{tabular}

Based on the above analysis conditions, structural analysis of the actual shape of the cooling ball with the flange and the primary nozzle was performed to evaluate the structural safety of the inner tank.

The restraint condition of the structural analysis is defined as the same condition as the simple shape, and the internal pressure is interpreted as 3.0MPa. Figure 8 shows Principal stress because of structural analysis on actual shape. As shown in the figure, the maximum stress was $11.17 \mathrm{MPa}$ at the bottom of the tank, and the stress in the tank was $7 \sim 8 \mathrm{MPa}$. Compared with the result of simplified form, the difference of $1 \sim 2 \mathrm{MPa}$ is shown by the shape of flange and control part.

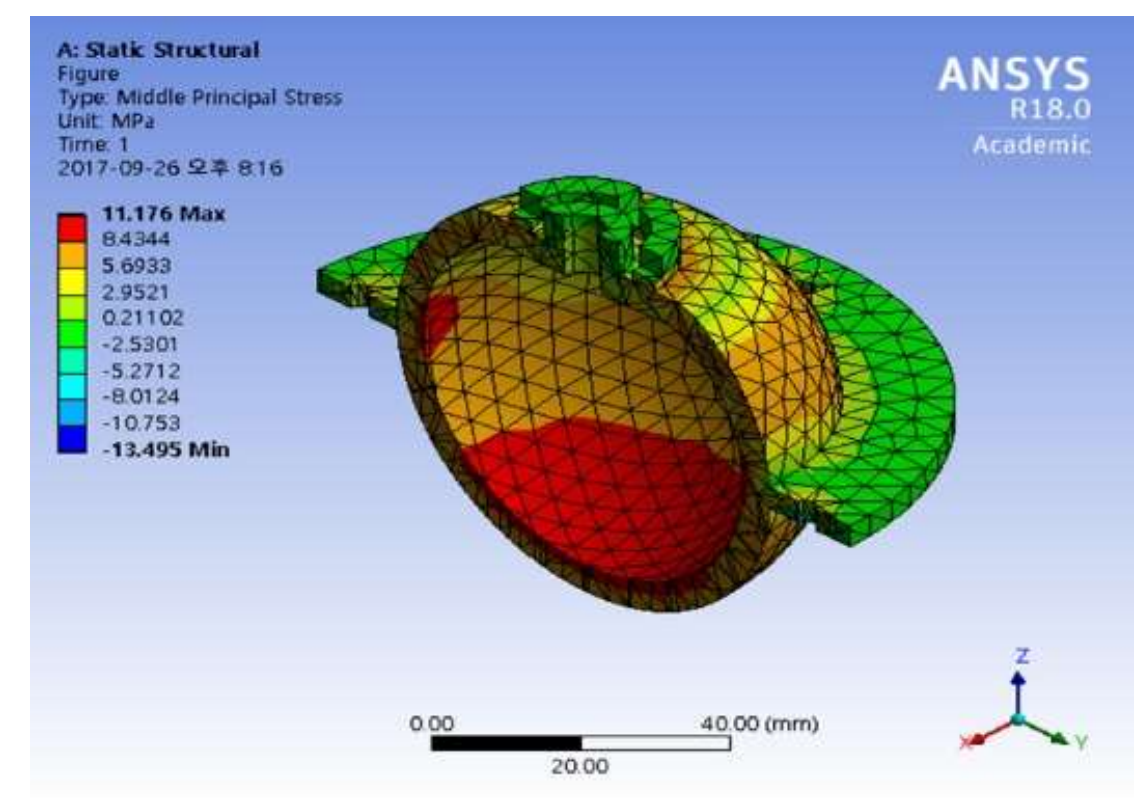

Figure 8. Analysis Result of Cooling Ball for Real Inner Shape (Principal Stress)

Figure 9 shows the deformation of the internal gas tank, with a deformation of 0.0024 $\mathrm{mm}$ in the downward direction. This indicates that even if 3.0MPa pressure is applied to the inner tank, the deformation occurs finely and it is considered that it has structural safety for the pressure. 


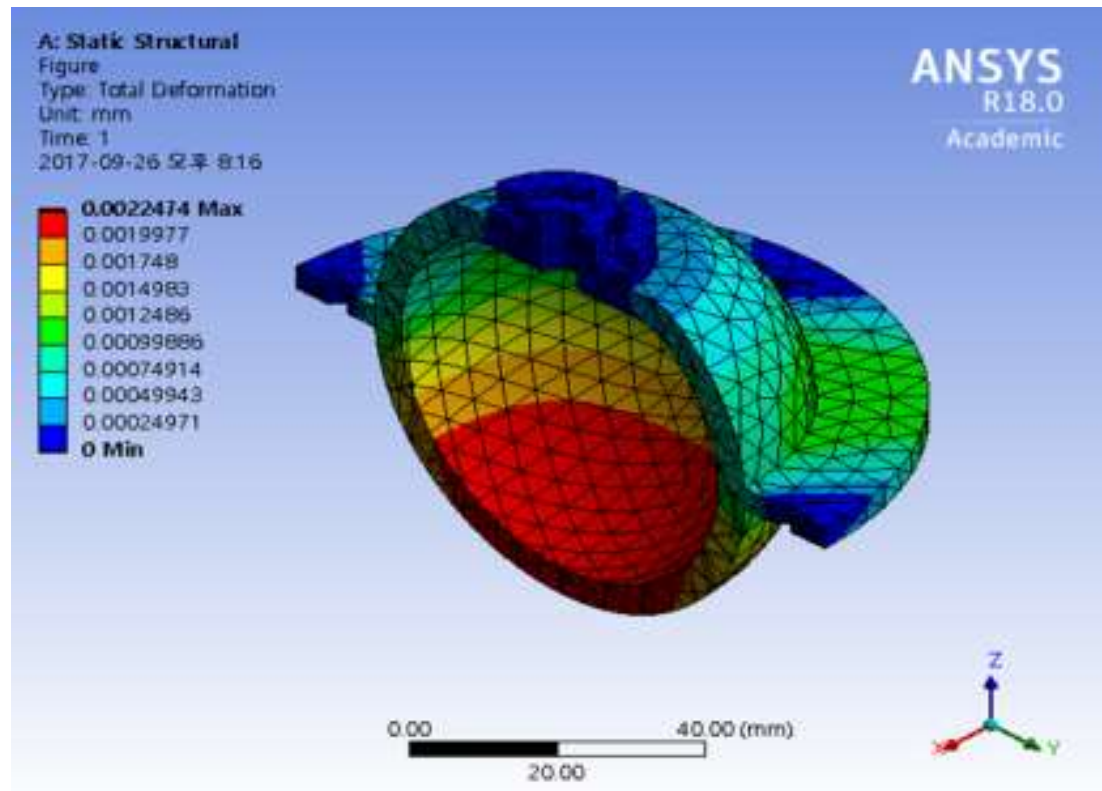

Figure 9. Analysis Result of Cooling Ball for Real Inner Shape(Deformation)

\subsection{Structural Analysis of External Features}

The outer casing of the cooling ball is immersed in the low-carbohydrate, protecting the internal gas tank and other internal devices. While low-carbohydrate power plants have different heights, and amounts of low-carbohydrate power plants, the structural analysis of the exterior casing of the cooling ball was carried out considering the maximum load. Since the stress analysis of the external carbon back is performed under the minimum conditions, it is not possible to ensure structural safety at the point of maximum $30 \mathrm{~m}$ of the carbon since it is not possible to secure structural stability due to the Buckling phenomena caused by the high carbonate height.

Coal density was 1,506 , and its height was $30 \mathrm{~m}$, making it possible to select $0.443 \mathrm{MPa}$ of external pressure on the cooling ball. As stated in the theory, the outer casing is considered a shell structure if the outer casing is 10 times smaller than the diameter $(\mathrm{t})$, so that the outer casing of the cooling ball is of diameter (d) and thickness (d). The structural analysis used the same ANSYS R 18.0 as the internal tank and provided the condition for external pressure to be applied at $0.443 \mathrm{MPa}[10]$.

Table 3. The Thin Shell Classification of Pressure Vessel for Cooling Ball Outer Shape

\begin{tabular}{|c|c|c|c|c|}
\hline Division & $\mathrm{t}(\mathrm{mm})$ & $\mathrm{d}_{\mathrm{i}}(\mathrm{mm})$ & $\mathrm{t} / \mathrm{d}$ & Standard \\
\hline $\begin{array}{c}\text { Outer } \\
\text { Shape }\end{array}$ & 5 & 160 & 0.0313 & $\begin{array}{c}\mathrm{t} / \mathrm{d} \leq 1 / 10 \\
\text { to shell }\end{array}$ \\
\hline
\end{tabular}

Figure 10 shows the mesh of the outer case, divided into 17,000 pieces. 


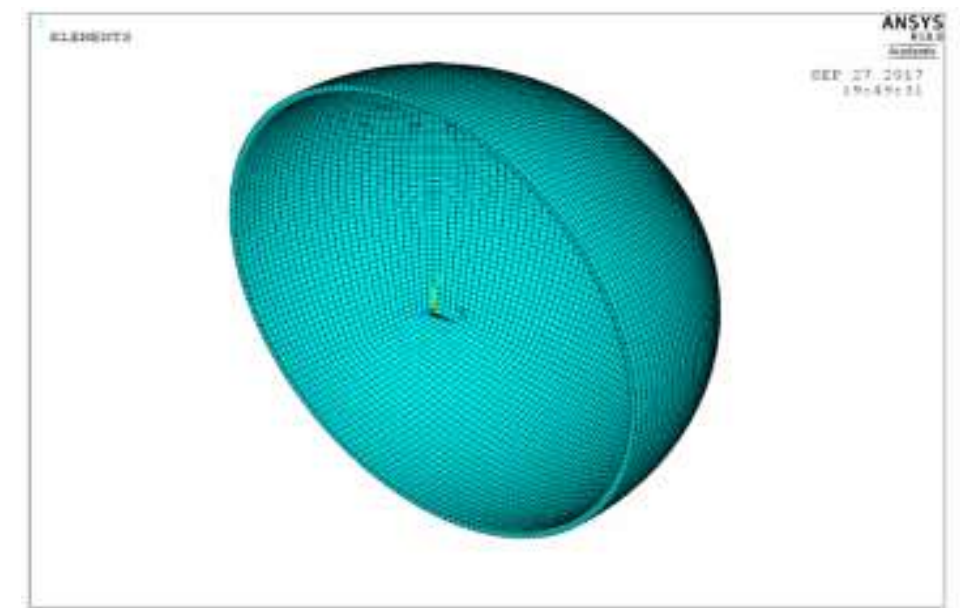

Figure 10. Mesh of Outside Case Simplified (ISO view)

Figures 11 and 12 show the result of Principal Stress analysis. The unit is MPa. As shown in the figure, the inner surface has a maximum stress of 7.7MPa and the outer surface has a stress of 7.48MPa.

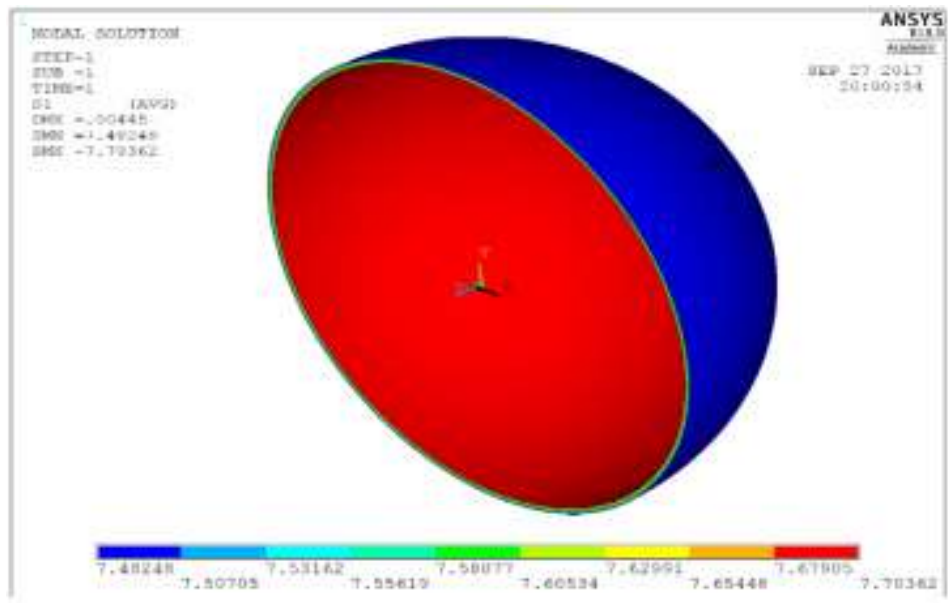

Figure 11. Analysis Result of Cooling Ball (ISO View)

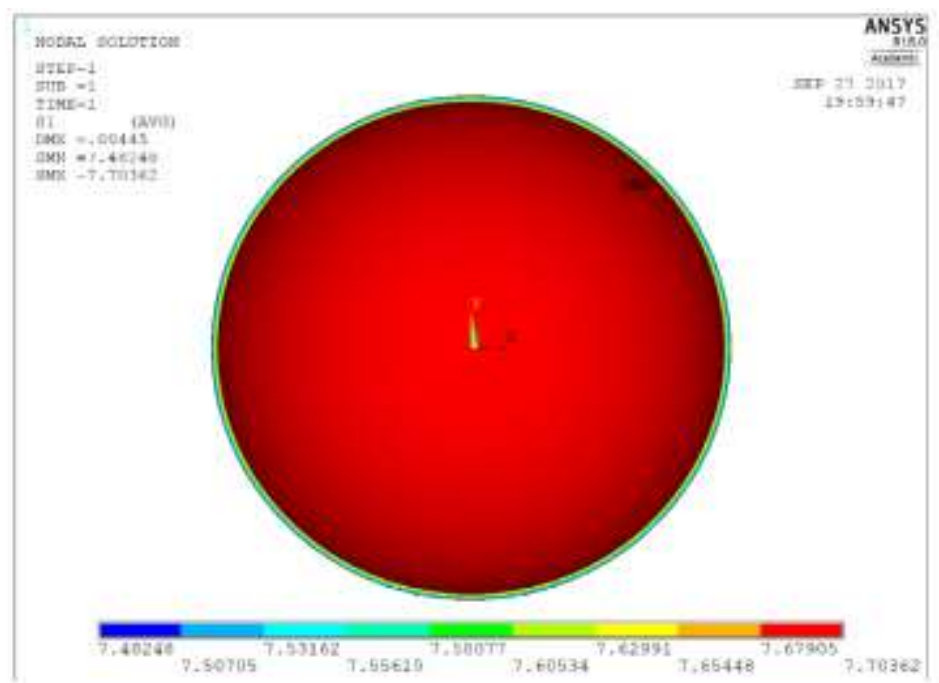

Figure 12. Analysis Result of Cooling Ball (Inside View) 
Table 4 compares the theoretical calculation with the ANSYS result. In theory, the error in the results was 2.67 percent, a good result.

Table 4. The Comparison of Calculated Stress and Analyzed Stress

\begin{tabular}{|c|c|}
\hline Division & Stress \\
\hline Theoretical Value & $7.50 \mathrm{Mpa}$ \\
\hline Interpreted Value & $7.70 \mathrm{Mpa}$ \\
\hline Error & $2.67 \%$ \\
\hline
\end{tabular}

Structural analysis was performed for the actual features based on the above analysis conditions. The outer casing is equipped with internal fittings, solenoid valves, and controls, so it has a complicated structure.

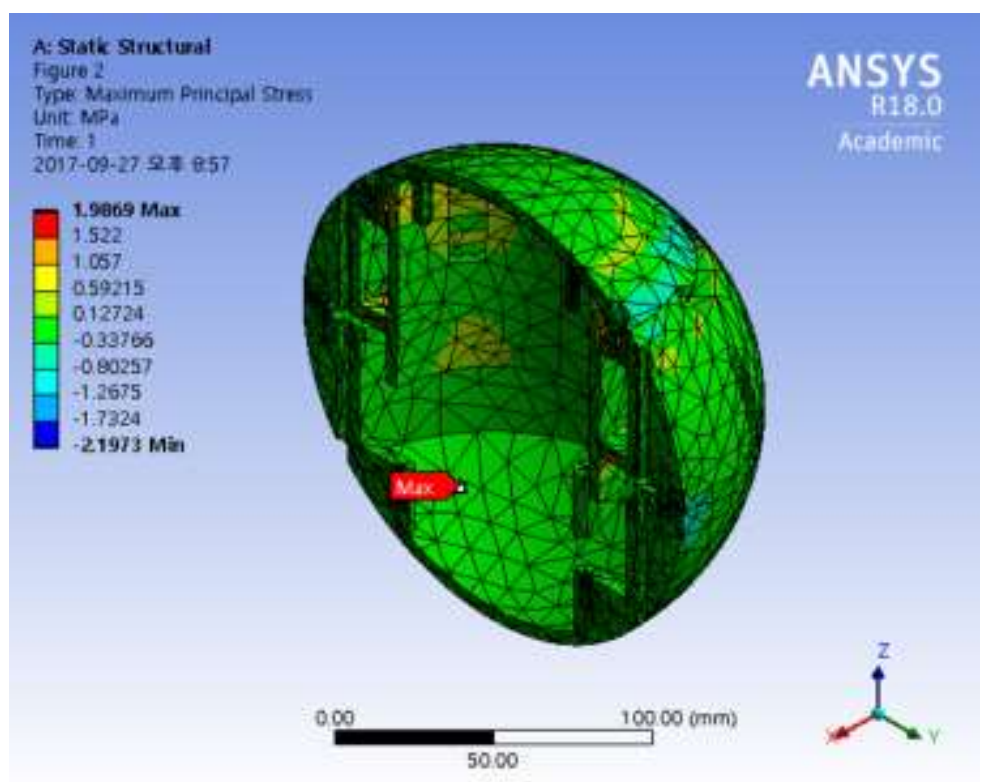

\section{Figure 13. Analysis Result of Cooling Ball for Real Outside Shape (Principal Stress)}

As shown in Figure 13, the maximum stress is $1.9 \mathrm{MPa}$, and the stress is concentrated in the joint of the outer case. The reason why the stress is low is judged as the influence of the mounting of various internal devices inside. Figure 14 shows the deformation of the outer case and the deformation of the outer case of the pressure by $0.00025 \mathrm{~mm}$ occurred at the part where the control device is mounted. Therefore, it is considered that it has the structural safety against external pressure. 


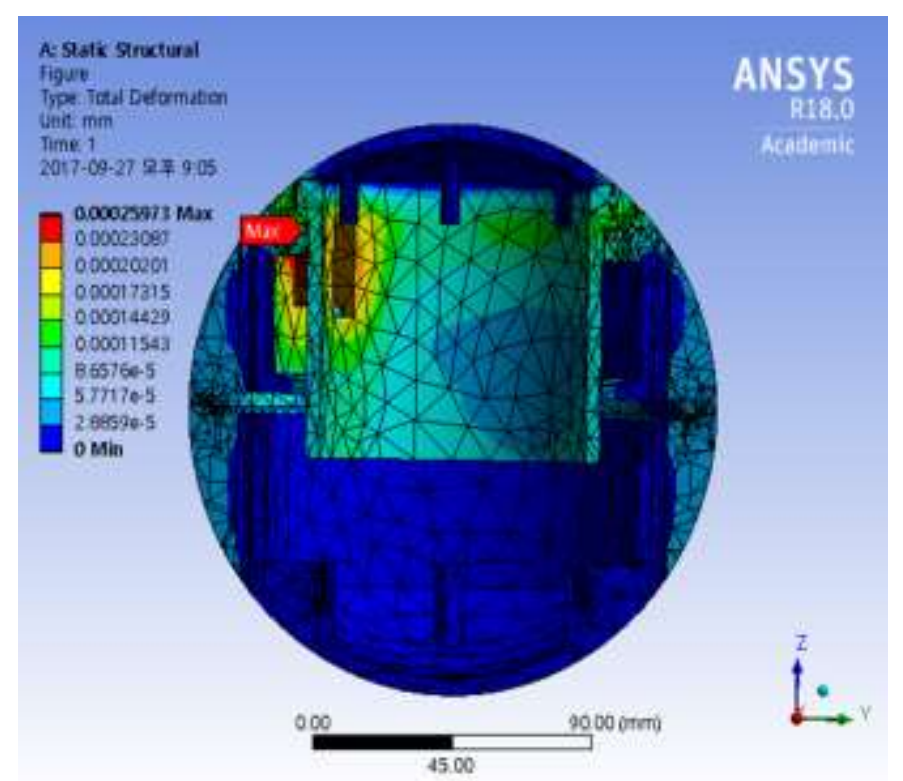

\section{Figure 14. Analysis Result of Cooling Ball for Real Outside Shape (Deformation)}

As a result of structural analysis of the actual internal pressure and structural analysis of the external casing, the internal tank with the maximum variation of $0.0024 \mathrm{MPa}$ is the maximum stress $11.17 \mathrm{MPa}$ and the maximum displacement is the maximum.

Table 5. Analysis Result of Real Shape

\begin{tabular}{|c|c|c|}
\hline Division & $\begin{array}{c}\text { Actual Internal } \\
\text { Tank }\end{array}$ & $\begin{array}{c}\text { Actual External } \\
\text { Tank }\end{array}$ \\
\hline Maximum Stress & $11.17 \mathrm{Mpa}$ & $1.9 \mathrm{Mpa}$ \\
\hline Maximum Deformation & $0.0024 \mathrm{~mm}$ & $0.00025 \mathrm{~mm}$ \\
\hline Structural Safety & $\begin{array}{c}\text { structural } \\
\text { stability }\end{array}$ & $\begin{array}{c}\text { structural } \\
\text { stability }\end{array}$ \\
\hline
\end{tabular}

\section{Conclusion}

In this study, the ANSYS results of theoretical equations and simple types of pressure vessels were compared for safety analysis on internal tank and external casing under pressure. Based on this validation, structural safety is assessed by analyzing the stress analysis and the variation rate for the actual features. The analysis results show that the internal tank has safety for internal pressure, and the external casing of the cooling ball also holds safety for the external pressure. In the future, this study plans to carry out structural analyses considering materials and temperature considerations.

\section{Acknowledgments}

This study was carried out with support from the Small and Medium Business Administration, "Development of a Low Fuel Spontaneous Ignition Prevention System Using Smart Cooling Ball (Project Number: S2447242)". 


\section{References}

[1] C. J. Kim, I. S. Park and C. H. Sohn, "Numerical Study on the Phenomenon of Spontaneous Ignition of Coal Stockpile", The Korean society of mechanical engineers, vol. 34, no. 7, (2010), pp. 721-727.

[2] S. Gond, Akhilesh, A. Singh and V. Sharma, "Design and Analysis of the Pressure Vessel," International Journal of Scientific \& Engineering Research, vol. 5, no. 4, (2014), pp. 939-942.

[3] H. M. Lee, S. W. Park and J. K. Lee, "Structural Analysis for Spherical Pressure Hull of Deep Manned Submersible," Society for Computational Design and Engineering, vol. 20, no. 4, (2015), pp. 412-419.

[4] A. R. Pendbhaje, M. Gaikwad, N. Deshmukh and R. Patil "Design and Analusis of Pressure Vessel," International Journal of Innovative Research in Technology \& Science, vol 2, no 3, (2014), pp. 28-34.

[5] B. S. U. SoYul and D. N. SoYul Standard Mechanical Design Chart Handbook, 5th Ed., Daekwang Seorim Publishing Co., (2009).

[6] J. S. Lee and K. M. Jang "A Study on the Propensity for the Deformation and Failure of a Small Pressurized Cylinder," The Korean Institute of Gas, vol. 23, no. 3, (2014), pp.146-149.

[7] D, J, Choi "The Development of Structural Design and Manufacturing for Cryogenic Storage Tank," Korea Maritime and Ocean University, Major of Mechanical Systems Engineering, (205) October.

[8] ANSYS, Inc. "ANSYS Theory Reference Release 5.6," 11Ed, (1999) November.

[9] S. Moaveni "Finite element analysis theory and application with ANSYS," 3rd,. ITC, (2008).

[10] B. Moghtaderi, B. Z. Dlugogorski and E. M. Kennedy "Effects of Wind Flow on Self-Heating Characteristics of Coal Stockpiles," Institution of Chemical Engineers, vol 78, Part B, November. (2000).

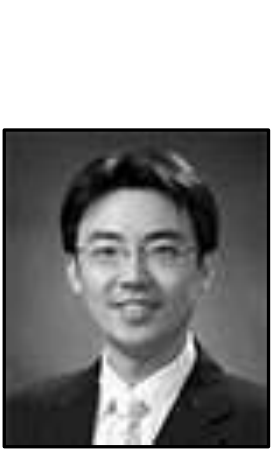

\section{Authors}

Min-Seok Jie, he graduated from the Ph.d degree in the department of avionics Engineering from Korea Aerospace University in 2006. he is Hanseo University Avionics Engineering Professor in to the present in 2008 .

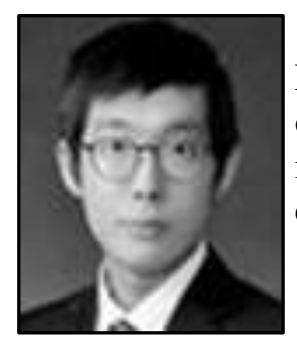

Seung-Hun Kim, he is a master's degree in Aeronautical System Engineering, Hanseo University. He graduated from the Department of Aeronautical and Mechanical Engineering, Hanseo University. He is studying Kalman filters, embedded systems, and smart network communications.

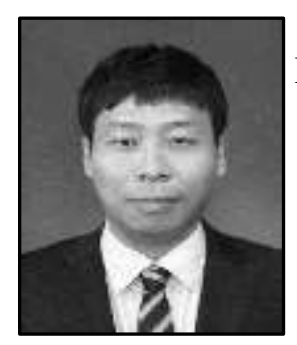

Chan-Sub Yeum, he earned an electronics degree from Chungbuk National University in 2008.

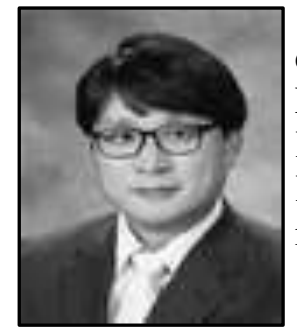

Won-Hyuck Choi (Corresponding author), He received the Ph.D. degree in avionics from Korea Aerospace University, Korea. He was a Professor of smart network at Doowon Technical University College, Korea. currently, he is Professor of avionics at Hanseo University, Korea, where he has been since 2014. His present research interests include embedded system, home network. 
International Journal of Advanced Science and Technology

Vol.116 (2018) 